\title{
Mechanical Characteristics of Cement Paste in the Presence of Carbon Nanotubes and Silica Oxide Nanoparticles: An Experimental Study
}

\author{
Moses Karakouzian ${ }^{1, *} *$, Visar Farhangi ${ }^{1, *}$, , Marzieh Ramezani Farani ${ }^{2, *}$, Alireza Joshaghani ${ }^{3}(\mathbb{D}$, \\ Mehdi Zadehmohamad ${ }^{4}$ and Mohammad Ahmadzadeh ${ }^{5}$ \\ 1 Department of Civil and Environmental Engineering and Construction, University of Nevada, \\ Las Vegas, NV 89154, USA \\ 2 School of Chemical Engineering, College of Engineering, University of Tehran, Tehran 1417466191, Iran \\ 3 Zachry Department of Civil Engineering, Texas A\&M University, College Station, TX 77843, USA; \\ joshaghani@tamu.edu \\ 4 Department of Civil and Environmental Engineering, Louisiana State University, \\ Baton Rouge, LA 70803, USA; mzadeh2@lsu.edu \\ 5 Department of Civil Engineering, Sharif University of Technology, International Campus, \\ Tehran 9417-76655, Iran; m.ahmadzadeh@student.sharif.edu \\ * Correspondence: mkar@unlv.nevada.edu (M.K.); farhangi@unlv.nevada.edu (V.F.); m.r.farani@ut.ac.ir (M.R.F.)
}

Citation: Karakouzian, M.; Farhangi, V.; Farani, M.R.; Joshaghani, A.; Zadehmohamad, M.; Ahmadzadeh, M. Mechanical Characteristics of Cement Paste in the Presence of Carbon Nanotubes and Silica Oxide Nanoparticles: An Experimental Study. Materials 2021, 14, 1347. https://doi.org/10.3390/ma14061347

Academic Editor: Jun Zhang

Received: 12 February 2021

Accepted: 9 March 2021

Published: 11 March 2021

Publisher's Note: MDPI stays neutral with regard to jurisdictional claims in published maps and institutional affiliations.

Copyright: (c) 2021 by the authors. Licensee MDPI, Basel, Switzerland. This article is an open access article distributed under the terms and conditions of the Creative Commons Attribution (CC BY) license (https:// creativecommons.org/licenses/by/ $4.0 /)$.

\begin{abstract}
Considering the remarkable characteristics of nanomaterials, previous research studies investigated the effects of incorporating different types of these materials on improving the concrete properties. However, further studies are required to evaluate the complementary hybridization and synergistic influence of nanomaterials. In this research, the combined effect of adding nano silica particles (NS) and multi-walled carbon nanotubes (MWCNT) on enhancing both the compressive and flexural strengths of the cement paste was investigated. Moreover, the morphology of the interface between cement paste and aggregates was studied by scanning electron microscopy (SEM). The mixtures were prepared using three different portions of MWCNT and NS. Electron microscopy images indicated a uniform distribution of nanoparticles in the cement matrix, enhanced hydration reactions, and increased density. Based on the experiments' outcomes, the combined utilization of silica and carbon nanomaterials in the cement paste did not necessarily result in the maximum compressive and flexural strengths. Furthermore, it was observed that the use of higher percentages of pristine NS in the absence of MWCNT can lead to further enhancement of strength properties of the cement paste.
\end{abstract}

Keywords: silica nanoparticles; carbon nanotube; compressive strength; flexural strength

\section{Introduction}

Presently, nanotechnology has been gaining wide attention for the use in construction materials. The advent of this technology in the construction industry has also been accompanied by considerable advancements in the building industry. The ultimate goal of using nanomaterials in the construction industry is to develop high-performance building mixtures as multi-purpose materials [1,2]. Such multifunctional properties of nanomaterials are the most important advantages of using nanotechnology compared to other approaches and common materials [3-6]. Some shortcomings of Portland cement, such as low values of flexural strength, ductility, and toughness, along with the resistance issues in interaction with chemicals, raise concerns regarding the reliability and durability of this material [7-14]. Thus, using nanomaterials along with the cementitious materials can address these issues and significantly increase the mechanical properties of concrete.

In previous investigations, great attention has been paid to the effect of using nano silica particles (NS) on the mechanical properties of concrete and cement. In this regard, 
Li et al. [15] studied the effect of NS on the mechanical behavior and microstructure of ordinary Portland cement (OPC) binary blends. They reported that adding $1.0 \mathrm{wt} . \%$ of NS considerably reduces the setting time and improves OPC's strength. Based on their observations using mercury intrusion porosimetry (MIP) test and scanning electron microscopy (SEM), NS also enhances the binding within the hydrates and decreases the porosity. In another effort, Sargam and Wang [16] investigated the compressive strength, heat of hydration, and flowability of cement paste in the presence of NS dispersed with seven dispersants. They used polycarboxylate ether (PCE) based superplasticizer, sodium dodecyl sulfate (SDS), and anionic surfactants, in addition to Tritons (TX114, TX100, and TX405) and Tweens (T20 and T40). Based on the outcomes of this study, the hydration between cement and NS can be accelerated using PCE along with another surfactant. Moreover, they asserted that the compressive strength could be improved by using higher space ratios of cement-TX405 paste. Najigivi et al. [17] conducted a study on the impacts of using two types of NS on the compressive strength and workability of binary blended concrete cured in lime and water solutions. They examined the use of $\mathrm{SiO}_{2}$ nanoparticles with different ratios. They reported a reduction in the workability of the binary blends using $\mathrm{SiO}_{2}$ nanoparticles. Following the outcome of the hardened concrete test, the optimal substitution level of the cement paste was reported equal to $1.0 \mathrm{wt} . \%$ of cement. The ultimate compressive strength of the blended concrete was measured at the replacement level of $2.0 \mathrm{wt} . \%$. The forming of extra calcium-silicate-hydrate (C-S-H) had the main role in improving the mechanical characteristics of concrete using NS. Based on other research studies [18-20], the effects of NS on the physical properties of concrete are stronger than those of silica fume. Both physical and pozzolanic aspects of NS are critical in developing concrete with ultra-high-performance characteristics. Mohammadyan-Yasouj and Ghaderi [21] investigated the application of carbon nanotubes (CNT) along with basalt fiber (BF) and waste glass power (WGP) on concrete's mechanical characteristics. They highlighted the ternary application of these materials in the presence of NS. According to the outcomes of flexural, compressive, and water absorption tests along with the results of microscopy images, they mentioned that, by adding $0.1 \%$ CNT, $0.2 \%$ BF, and $20 \%$ WGP, a denser concrete with higher mechanical properties could be produced. Stynoski et al. [22] performed a comprehensive study on OPC mortar containing CNT, silica fume, and carbon fibers in an effort to analyze the ductility and crack width of cement paste. They specifically considered the interfacial transition zone within hydrated cement and fibers that can include a higher amount of calcium hydroxide and affect the porosity. They reported that the use of silica fume improves the fracture performance of mixtures in the presence of carbon fibers and CNT. Wang et al. [23] stated that cement paste with nanoparticles had more densified structures compared to the plain cement paste due to the reduction in the amount of pores and the presence of higher amount of $\mathrm{Ca}(\mathrm{OH})_{2}$ crystals along with enhancing the C-S-H quantity.

The influence of incorporating dispersed CNT on the mechanical characteristics of the cement paste and concrete was further investigated in many studies. CNT's diameter usually ranges $0.5-100 \mathrm{~nm}$ as a type of nanomaterials with single- or multi-cylindrical layers. CNTs are characterized by their mechanical properties with a tensile strength range close to $200 \mathrm{GPa}$, which is about 100 times higher than steel. Their elastic modulus is greater than the $1 \mathrm{TPa}$, although their density is almost $15 \%$ of steel. Application of nanotechnology and fibers to improve the mechanical properties of self-compacting concrete (SCC) were assessed in several studies [24-28]. Fly ash (FA) as a sustainable material [29] can also be used along with nanomaterials. Accordingly, Aydin et al. [30] investigated the synergistic effect of CNT and NS in the presence of FA on flexural and compressive strengths of SCC. They reported an adverse impact of using NS on fresh concrete's properties, considering the high water requirement. Although, the combined effect of using FA and NS not only increased the SCC's mechanical properties, but also reduced FA's bleeding and segregation effects by $40 \%$. Wille and Loh [31] examined the application of multi-walled carbon nanotubes (MWCNT) to enhance the bond within the steel fibers and the ultra-high-performance 
concrete's (UHPC's) matrix by improving the packing density. Following their study, a relatively low concentration of MWCNT (e.g., $0.022 \%$ wt. \%) can considerably increase the bonding response of steel fibers. Wang et al. [32] asserted that the presence of CNT could improve OPC paste's characteristics, such as flexural strength, modulus of elasticity, and electrical conductivity. Additionally, using CNT enhances sensitivity of the piezoresistive reaction to the propagation of microcracks in the cement paste. Such characteristics of CNT highlights its performance compared to other commonly used fibers to reinforce composites. The outstanding CNT properties strengthen the cement paste against the occurrence of early-age microcracks [33]. Joshaghani [34] assessed the performance of titanium dioxide $\left(\mathrm{TiO}_{2}\right)$ and carbon-nanofibers (CNF) singularly and simultaneously. He reported that concrete samples containing CNF were improved in terms of mechanical properties. The reason was attributed to the bridging effect of the CNFs for microcracks and filler effect. Incorporating both $\mathrm{TiO}_{2}$ and $\mathrm{CNF}$ at the same time would not necessarily increase the strength. The decrease in the strength could be due to the agglomeration and deficiencies caused by the dispersion of $\mathrm{TiO}_{2}$ particles and CNF. Moreover, Kang et al. [35], and Vesmawala et al. [36] proposed a significant enhancement of cement mechanical properties by adding CNTs. In another research, $\mathrm{Hu}$ et al. and Vidivelli et al. [37,38] reported durability improvements using CNT in the cement composites. Konsta-Gdoutos et al. [39], and Praveen et al. [40] proposed significant porosity reduction and reinforced matrix enhancement by adding C-S-H gel. The application MWCNT resulted in further uniform distribution of pore size along with tension load-transfer by bridging action [41,42]. Additionally, CNT reduced the shrinkage in the heating procedure of the autoclaved aerated concrete (AAC) [43].

Developing hybrid materials using the nanotechnology method enhances both the performance and durability of the produced material $[44,45]$. It also provides an environmentallyfriendly approach by minimizing natural resources as conventional construction materials [46-50]. Sikora et al. [51] investigated the effects of using MWCNT coated with NS on the cement pastes subjected to elevated temperature up to $600{ }^{\circ} \mathrm{C}$. They found that incorporating MWCNT and NS with the optimum amount equal to $0.125 \mathrm{wt} . \%$ of the cement paste was advantageous compared to the use of pristine MWCNT. The research team found an increase in the binding ability within the nanotubes and cement matrices. On the other hand, excessive use of MWCNT and NS in the cement paste could reduce the thermal capacity due to the nanomaterial's agglomeration. Narasimman et al. [52] studied the effects of incorporating combined CNT and NS materials on the lightweight concrete's compressive strength. CNT and NS as nano reinforcement fillers were used along with expanded clay to improve the compressive strength by applying the ultrasonication method. They utilized different ratios of CNT and NS with the optimal replacement level of these reinforcement fillers equal to $3 \%$ of cement paste. The research team reported that the maximum 28 -day compressive strength was $10.7 \mathrm{MPa}$ by using $2 \%$ CNT and $1 \%$ NS. In addition, they asserted that using the pristine CNT adversely affected the 28-day compressive strength. Garg et al. [53] reported that the combination of NS with low fractions of $\mathrm{CNT}$ in the cement paste improved the durability of concrete and enhanced the sensing capability of the smart concrete.

These findings illustrate the remarkable advantages of utilizing different types of nanoparticles to enhance the concrete properties. However, more research studies are required to investigate the effects of using nanomaterials to address the potential deficiencies of cement paste and further strengthen the concrete characteristics. In the present study, the effects of different ratios of CNT and NS on the mechanical properties were investigated. In addition, the morphology was examined by transmission electron microscopy (TEM). Then, scanning electron microscope (SEM) images were analyzed to illustrate nanoparticles' distribution in the cement matrix along with the filled pores. Finally, the compressive and flexural strength variations of the OPC paste in the presence of nanoparticles were tested. 


\section{Materials}

Type II Portland cement type was used in this study, which was acquired from Abyek Company, Abyek, Iran. This type of cement was as a moderate sulfate resistant cement and moderate heat of hydration in accordance with American Society for Testing and Materials (ASTM) C150 specifications [54]. The properties of Portland cement are summarized in Table 1. Polycarboxylate-based superplasticizer was used along with water in the mixture. The required amount of water to perform the hydration reactions with the related compounds in the cement was taken into consideration. Following the ASTM C109 [55] standard, the water-cement and aggregate-cement ratios of 0.30 and 2.65 were used, respectively.

Table 1. Chemical compositions of the Portland cement type II (wt.\%).

\begin{tabular}{cccccccccc}
\hline Material & $\mathrm{Al}_{2} \mathrm{O}_{3}$ & $\mathrm{SiO}_{2}$ & $\mathrm{MgO}$ & $\mathrm{CaO}$ & $\mathrm{Fe}_{2} \mathrm{O}_{3}$ & $\mathbf{K}_{2} \mathrm{O}$ & $\mathbf{N a}_{2} \mathbf{O}$ & $\mathbf{S O}_{3}$ & $\mathrm{LOI}$ \\
\hline Portland Cement & 4.8 & 21.3 & 2.4 & 64.0 & 3.9 & 0.7 & 0.4 & 2.1 & 1.1 \\
\hline
\end{tabular}

MWCNT were acquired from Sigma-Aldrich Company and NS were prepared by Shanghai Aladdin biochemical technology company, Shanghai, China. The physical properties of the MWCNT and NS are presented in Table 2.

Table 2. Material properties of multi-walled carbon nanotubes (MWCNT) and nanoparticles $\mathrm{SiO}_{2}$ (NS).

\begin{tabular}{cccccc}
\hline Product Name & $\begin{array}{c}\text { Appearance } \\
\text { (Color) }\end{array}$ & $\begin{array}{c}\text { Diameter } \\
(\mathbf{n m})\end{array}$ & $\begin{array}{c}\text { Specific } \\
\text { Surface Area } \\
\left(\mathbf{m}^{\mathbf{2}} / \mathbf{g}\right)\end{array}$ & $\begin{array}{c}\text { Purity } \\
\mathbf{( \% )}\end{array}$ & $\begin{array}{c}\text { Length } \\
(\boldsymbol{\mu m})\end{array}$ \\
\hline $\begin{array}{c}\text { Multi-walled carbon } \\
\text { Nanotubes (MWCNT) }\end{array}$ & Black & $20-40$ & $80-140$ & $>98$ & $5-15$ \\
Nanoparticles $\mathrm{SiO}_{2}$ (NS) & White Powder & $7-40$ & 300 & 99.8 & - \\
\hline
\end{tabular}

The high-resolution transmission electron microscope (HRTEM) by the JEOL Ltd. (JEM-2100, Akishima, Japan) at $100 \mathrm{kV}$ was utilized in this study to analyze the morphology of MWCNT. As shown in Figure 1a, MWCNT had a tubular shape with diameter ranging 20-40 nm. The HRTEM micrograph demonstrated that the obtained NS has a spherical shape with few agglomerations (see Figure 1b).

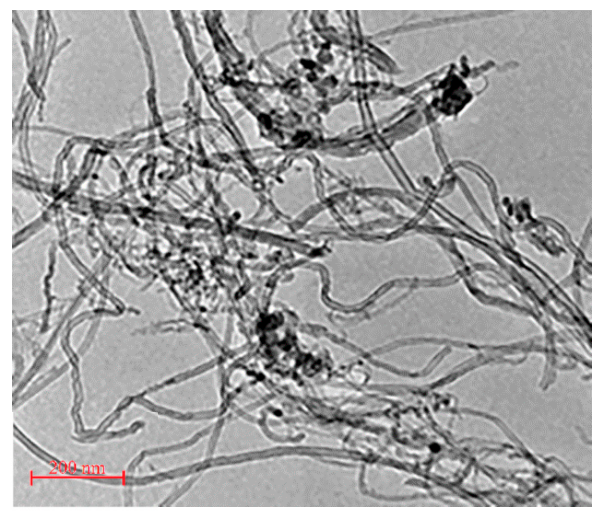

(a)

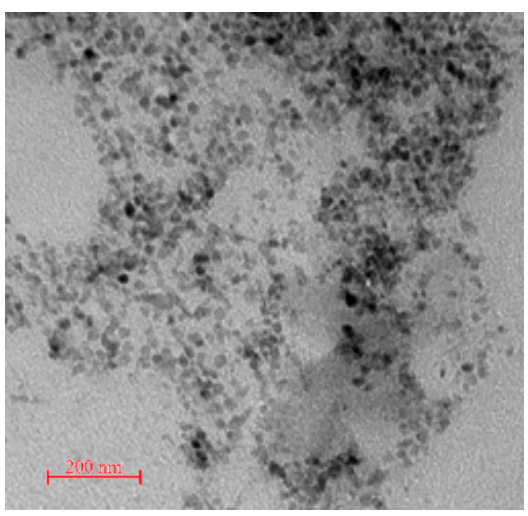

(b)

Figure 1. Morphology analysis with HRTEM: (a) CNT; and (b) nanoparticles $\mathrm{SiO}_{2}$ (NS).

MWCNT were also examined by X-ray diffraction (XRD), to evaluate the mineral compositions using Bruker D8-Advance diffractometer with monochromatic CuKa radiation, Bruker Corporation, Billerica, Massachusetts, USA. The XRD patterns of MWCNT and silica oxide nanoparticles are presented in Figure $2 a, b$, respectively. The diffraction peaks 
at $26.2^{\circ}$ and $43.2^{\circ}$ can be indexed to the (002) and (110) planes of MWCNT [38,56]. The particle size was measured as $5 \mathrm{~nm}$. The properties of the broad silica peak were observed at $2 \theta=22^{\circ}$ and illustrated the effect of amorphous silica [57,58].
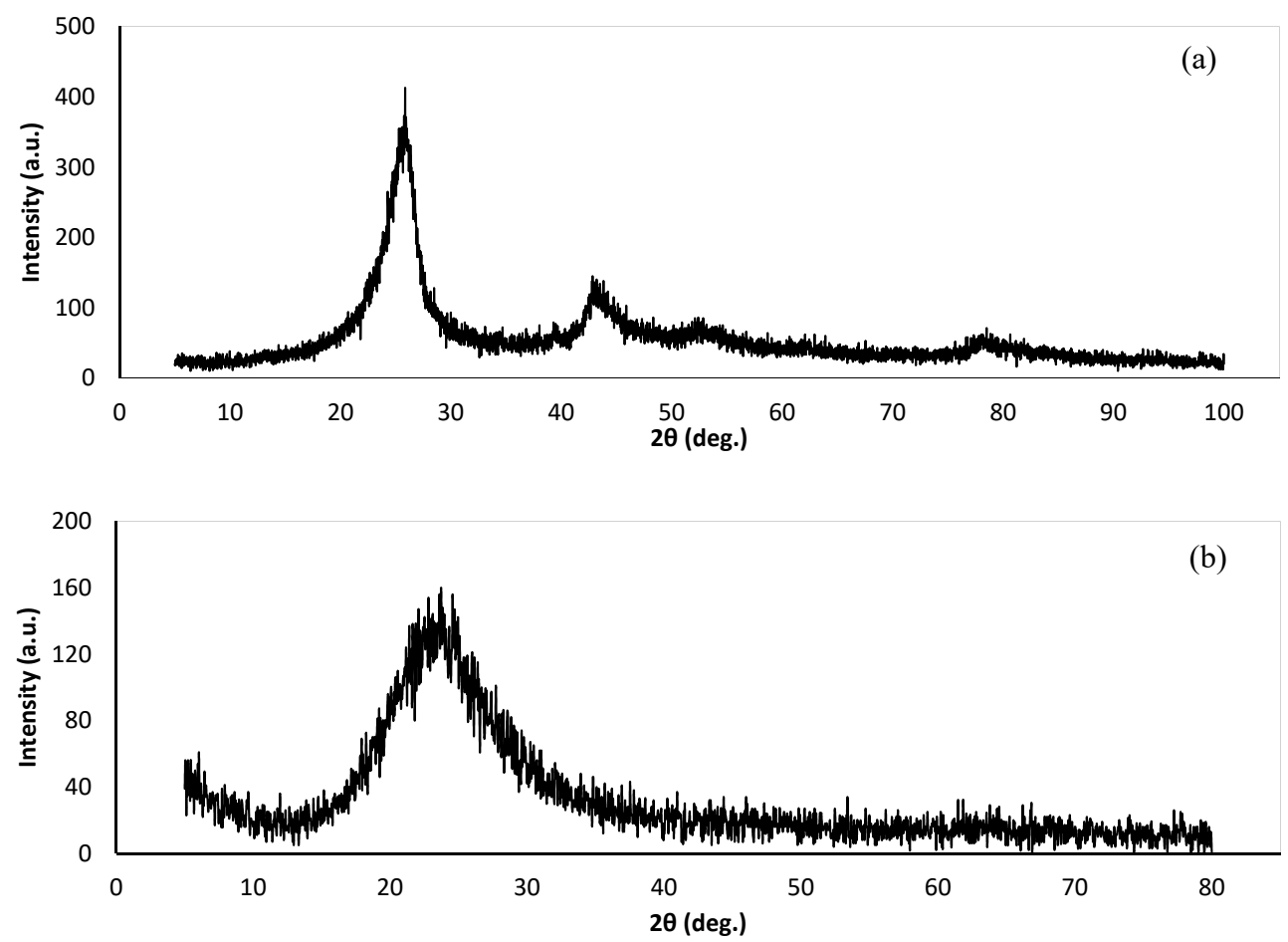

Figure 2. XRD diffraction pattern of: (a) CNT; and (b) $\mathrm{SiO}_{2}$ nanoparticles.

\section{Experimental Procedures}

\subsection{Dispersing the Nanoscale Uniformly in Water, and Workability}

Untreated nanoparticles are prone to aggregate (firmly-held clusters) due to the existence of considerable Van der Walls force along with the electrostatic force within the nanoparticles [59]. Moreover, such aggregation can cause defects in the matrix and reduce the cement paste's strengths. Ultrasonic dispersion processing is commonly used to enhance the dispensability of nanoparticles to produce a homogeneous cement paste [60]. According to previous studies, ultrasonic dispersion significantly improves the dispersing effect [61]. In this context, an ultrasonic disrupter was used in the present research to decrease the nanoparticles' agglomeration. The total allocated time for the sonication was $15 \mathrm{~min}$. Nanoparticles were added to distilled water and evenly stirred to be wetted completely. MWCNT were dispersed using a dual cavitation process, which is stirred for $10 \mathrm{~min}$ and then was ultra-sonicated for $5 \mathrm{~min}$ at room temperature $\left(25^{\circ} \mathrm{C}\right)$ with one-third of the mixing water. After stirring the nanoparticles in water, the ultrasonic disrupter (750 W, $20 \mathrm{kHz}$ ) was used to decrease the nanoparticles' agglomeration in the water. The dispersant agent and defamer were dissolved in water. The JJ-5 type cement mixer with 140 and $285 \mathrm{rpm}$ rotation rates along with the ZS-15 type vibrator (Wuxi Jiangong Test Co., Wuxi, China) were used for mixing the cement and nanoparticles' suspension. In the dispersion process, the suspension was kept in ice water to avoid foaming and heating during the sonication process. After the completion of the mixing process, the cement paste's workability was evaluated by performing a mini- slump test considering the limited amount of produced cement paste. The mini-slump test was performed according to the method proposed by Collins et al. [62]. In this matter, a miniature slump cone was used with a height of $57 \mathrm{~mm}$ and bottom and top diameters of 38 and $19 \mathrm{~mm}$, respectively. The slump diameter was reduced by $37.8 \%$ at $w / c=0.3$ by adding $2 \% \mathrm{SiO}_{2}$ and $0.3 \% \mathrm{CNT}$ to 
the cement paste. Therefore, the Polycarboxylate-based superplasticizer and the remaining water were added into the mixer to improve the workability $[63,64]$.

\subsection{Preparation of Cement Paste}

After the nanomaterials were dispersed in distilled water, the OPC cement was added to the mixture. The mixing operation was performed simultaneously for $2 \mathrm{~min}$ at high speed $(140 \mathrm{rpm})$ in the mixer. As an additional effort to effectively increase the dispersion of nanoparticles, the cement paste was stirred for an extra $2 \mathrm{~min}$ at the speed of $285 \mathrm{rpm}$. The prepared specimens are summarized in Table 3.

Table 3. Prepared specimens of the mixture design.

\begin{tabular}{ccccccc}
\hline Specimen ID & NS (wt.\%) & CNT (wt.\%) & Water (g) & OPC (g) & NS (g) & CNT (g) \\
\hline 1 (Control Mix) & 0.00 & 0.00 & 380 & 172 & 0.00 & 0.00 \\
$2 \mathrm{SiO}_{2}$ 0.0-CNT 0.3 & 0.00 & 0.30 & 380 & 172 & 0.00 & 0.51 \\
$3 \mathrm{SiO}_{2}$ 0.5-CNT 0.0 & 0.50 & 0.00 & 380 & 172 & 0.86 & 0.00 \\
$4 \mathrm{SiO}_{2}$ 0.5-CNT 0.06 & 0.50 & 0.06 & 380 & 172 & 0.86 & 0.10 \\
$5 \mathrm{SiO}_{2}$ 0.5-CNT 0.3 & 0.50 & 0.30 & 380 & 172 & 0.86 & 0.51 \\
$6 \mathrm{SiO}_{2} 2.0-\mathrm{CNT} \mathrm{0.0}$ & 2.00 & 0.00 & 380 & 172 & 3.44 & 0.00 \\
$7 \mathrm{SiO}_{2} 2.0-\mathrm{CNT} \mathrm{0.06}$ & 2.00 & 0.06 & 380 & 172 & 3.44 & 0.10 \\
$8 \mathrm{SiO}_{2} 2.0-\mathrm{CNT} \mathrm{0.3}$ & 2.00 & 0.30 & 380 & 172 & 3.44 & 0.51 \\
\hline
\end{tabular}

\subsection{Specimen Preparation}

The well-mixed cement paste was poured into the metal molds $(50 \mathrm{~mm} \times 50 \mathrm{~mm} \times 50 \mathrm{~mm}$ ) for compressive tests, and prisms with a size of $50 \mathrm{~mm} \times 50 \mathrm{~mm} \times 180 \mathrm{~mm}$ were used for flexural tests. The specimens were maintained in the laboratory, standard chamber, for $24 \mathrm{~h}$ at $23-25{ }^{\circ} \mathrm{C}$ and $95 \%$ humidity. The exposed surfaces were sealed using plastic sheets to avoid possible moisture loss. After this period, the molds were removed vertically to ensure no lateral disturbance could occur. In the next step, the specimens were kept in distilled water at the same temperature. The specimens' storage time under these conditions was recorded in 7- and 28-day intervals. Table 3 also shows the percentages of the used NS and MWCNT in the specimens.

\subsection{Testing Methods}

The compressive testing was conducted at 7 and 28 days after preparing the cubic specimens. The hydraulic mechanical testing system (MTS) was used to apply the controlled compressive load. The compressive strength was performed according to the ASTM C109/C109 M-11b specifications [65]. Strengths of three samples for each mixture design were measured, and the average value is reported as the compressive strength. In addition, the flexural capacity of specimens was measured using the bend tester to apply the controlled load on the long surface of prism specimens based on the ASTM C348-20 standard [66]. The load application on specimens was performed for 50-90 s using a maximum control rate of $0.1 \mathrm{~mm} / \mathrm{min}$. Similarly, the average values of the bending tests for each mixture were documented. After performing the mechanical tests, selected crushed specimens were used for conducting the SEM test. The SEM test was performed by S-4700 type, Hitachi, Chiyoda, Tokyo, Japan, device for characterization of nanoparticles' distribution in the matrix and distilled water. The SEM samples were acquired as remaining pieces with dimensions of $3 \mathrm{~mm} \times 5 \mathrm{~mm} \times 5 \mathrm{~mm}$ from the cube which was subjected to compression. Prior to the SEM test, a very thin layer $(1 \mathrm{~nm})$ was used to sputter-coat the fracture surface.

\section{Results and Discussion}

In this section, the compressive and flexural strengths of the cement paste at the ages of 7 and 28 days using different wt.\% of NC and MWCNT are discussed. Moreover, analyses of element distribution in the specimens along with the size and location of NS and MWCNT in the specimens are presented using SEM images. 


\subsection{Compressive Strength Test}

Figure 3 displays the measured compressive strength of specimens according to the experiments at the ages of 7 and 28 days. The results show that considerable changes in compressive strength were observed by adding nanoparticles to cement paste. In 7-day specimens, the test outcomes reveal that adding MWCNT could enhance the specimens' compressive strength, compared to the control mix. In this period, the highest increase was observed for specimens $\mathrm{SiO}_{2} 2.0-\mathrm{CNT} 0.0$ and $\mathrm{SiO}_{2} 0.5-\mathrm{CNT} 0.3$ with $111 \%$ and $108 \%$ improvements, respectively. In these specimens, MWCNT and NS had various wt.\%. The equal compressive strength of $\mathrm{SiO}_{2} \quad 0.5-\mathrm{CNT} 0.3$ and $\mathrm{SiO}_{2} \quad 0.5-\mathrm{CNT} 0.06$ indicates that variations of MWCNT cannot necessarily affect the cement paste's mechanical property by using $0.50 \mathrm{wt} . \%$ of NC.

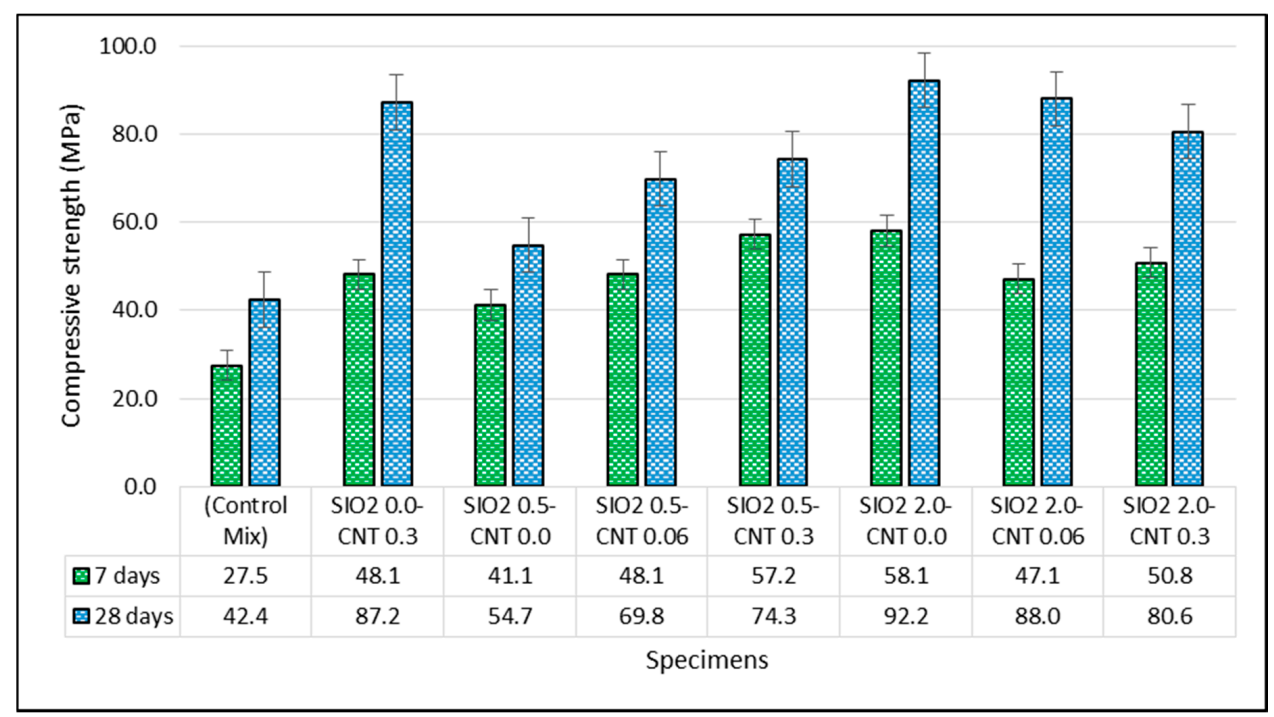

Figure 3. Compressive strength of cement paste specimens at the ages of 7 and 28 days.

In 28-day specimens, the results indicate that the addition of NS improved the compressive strength of the specimens. Such enhancements were more significant in specimens $\mathrm{SiO}_{2} 2.0-\mathrm{CNT} 0.06, \mathrm{SiO}_{2} 2.0-\mathrm{CNT} 0.0$, and $\mathrm{SiO}_{2}$ 0.0-CNT 0.3 compared to the other specimens. The greatest enhancement of compressive strength is reported in specimen $\mathrm{SiO}_{2} 2.0-\mathrm{CNT} 0.0$ with a $117 \%$ increase. Furthermore, it was observed that the compressive strength in specimens $\mathrm{SiO}_{2} 0.0-\mathrm{CNT} 0.3$ and $\mathrm{SiO}_{2} 2.0-\mathrm{CNT} 0.06$ are very close to each other, with $105 \%$ and $107 \%$ of improvement, respectively. Thus, adding NC in the mixture cannot ensure a distinguishable improvement in the cement paste's mechanical behavior in the presence of MWCNT.

On the other hand, by adding NS, the compressive strength was increased slightly more in the 28-day specimens compared to the-day specimens. In 7-day specimens, the ultimate increase in compressive strength was up to $58 \mathrm{MPa}$, which is a significant improvement compared to the control specimen with a strength of $27.5 \mathrm{MPa}$. Similarly, in the 28-day specimens, compressive strength was increased by almost $50 \mathrm{MPa}$. NS particles also improve the pozzolanic activity and reduce the porosity, which results in a more homogenous, compact, and denser microstructure, thus enhancing the compressive strength [67].

Comparing the measured values of the compressive strength shows that, for the constant amount of MWCNT equal to $0.3 \%$, in the presence of NS varying between $0 \%$ and $2.0 \%$, the 28 -day compressive strength was improved up to $87.2 \mathrm{MPa}$. In addition, it was observed that the maximum compressive strength value was achieved in the absence of MWCNT, as is reported for specimen $\mathrm{SiO}_{2}$ 2.0-CNT 0.0. This finding shows that the combination of NS and MWCNT cannot necessarily improve the compressive strength of concrete. In this regard, the presence of MWCNT as an additive to the cement with NS could adversely affect the compressive strength. The accelerating effect of adding NS 
to the cement paste was indirectly studied by controlling the changes in viscosity and rheological measurements [68]. Measurements of viscosity illustrate that incorporation of NS in the mortar and cement paste increases the water demand to maintain the same level of workability. Accordingly, Quercia et al. [69] asserted the direct relationship between water demand and workability. The high water demand of NS in the mixture can cause the negative effect on the mechanical characteristics of specimens, as shown in the results of the present study. Such a negative effect can also influence the degree of improvement with the binary use of MWCNT and NS in the cement paste.

Moreover, as reflected in this research, the use of MWCNT can lead to a partial reduction in the strength, despite increasing the MWCNT dosage. Accordingly, Sobolkina et al. [70] stated that the bridging of C-S-H phases varies based on the CNT type, which, to some extent, changes the effectiveness of incorporating CNT on mechanical characteristics of cement paste. Moreover, the presence of Van der Waals' force hinders uniform dispersion of CNT. Without a uniform dispersion, incorporating CNT cannot lead to promising results on improving the strength of cement paste. Zhou et al. [71] addressed this issue by using graphene oxide (GO) as a dispersant in the presence of CNT. The use of GO leads to pores refinement in the cement paste. The negative effect of CNT can be addressed by modifying the CNT's polymeric matrices in concrete. For instance, Güler et al. [72] modified the surface of CNT using polymeric surfactants such as Poly (ethylene glycol) (PEG), Polyvinyl alcohol (PVA), Dodecylamine-(DDA), and Polyvinylpyrrolidone (PVP) in an attempt to enhance concrete's mechanical properties. The use of such polymeric surfactants avoids the requirement for additional proves of CNT's surface, compared to other recommended different surfactants $[73,74]$. By implementing this modification, the strength can be improved up to $60 \%$, even for low dosages of CNT such as $0.05 \mathrm{wt} . \%$. The PVP surfactants had the most considerable influence on strength values compared to the two other stated surfactants.

\subsection{Flexural Strength Test}

The reported flexural strength values of the specimens in the 7- and 28-day periods are presented in Figure 4.

For the seven-day specimens, it was observed that adding NS and MWCNT improved the flexural strength, compared to the control mix. For example, $182 \%$ enhancement for specimen $\mathrm{SiO}_{2} 2.0-\mathrm{CNT} 0.0$ was observed. In this specimen, the notable increase in the flexural strength is recorded in the absence of MWCNT for a7-day period. This improvement with the highest percentages of NS can be attributed to excluding MWCNT from the cement paste. In this regard, some investigations revealed that the sliding of MWCNT from the paste's matrix during tensile and flexural loads causes a weak bond between MWCNT and the matrix [75], which cannot improve the strength of cement paste containing NS. Furthermore, it was observed that, during the 28-day curing period, adding different $\mathrm{wt} . \%$ of nanoparticles to the cement paste improved the flexural strength, in comparison to the control mix. In this period, the minimum of $49.4 \%$ improvement and the maximum of $151 \%$ enhancement of flexural capacity were recorded by adding nanoparticles. The most remarkable flexural strength after 28 days of improvement was measured in specimen $\mathrm{SiO}_{2}$ 2.0-CNT 0.0. The flexural strength of the specimens at the age of 28 days showed a comparable improvement trend with the 7-day specimens. Moreover, it was found that the flexural strength declined when adding more dosages of MWCNT for the specimens with the same $2.0 \mathrm{wt} . \%$ of NS, e.g., specimens $\mathrm{SiO}_{2} 2.0-\mathrm{CNT} 0.06$ and $\mathrm{SiO}_{2}$ 2.0-CNT 0.3.

The similar trend in reduction of flexural strength was observed for the samples with the constant $0.5 \mathrm{wt} . \%$ of NS containing MWCNT. For instance, by addition of MWCNT, from specimen $\mathrm{SiO}_{2}$ 0.5-CNT 0.0 to specimen $\mathrm{SiO}_{2}$ 0.5-CNT 0.3, the flexural strength was reduced by $4.7 \mathrm{MPa}$. This reduction in the flexural strength highlights the fact that, notwithstanding the high tensile strength of MWCNT, its effect on the flexural strength is only evident if MWCNT is separately incorporated. By adding MWCNT to the cement 
paste in the presence of NS, the flexural strength is reduced in the case of using $\mathrm{SiO}_{2} 2.0$ or $\mathrm{SiO}_{2}$ 0.5, considering the comparable error margins of experiments. This finding displays the fact that the synergistic effect of using these nanomaterials in the cement past cannot always be positive. Aydin et al. [30] attributed the negative effect of CNT to its high water demand. They stated that the use of fly ash in addition to MWCNT and NS can address this issue. The outcome of the bending tests in the present study shows that such a binary incorporation of MWCNT and NS cannot always have the most influential effect on improving the cement paste's flexural strength.

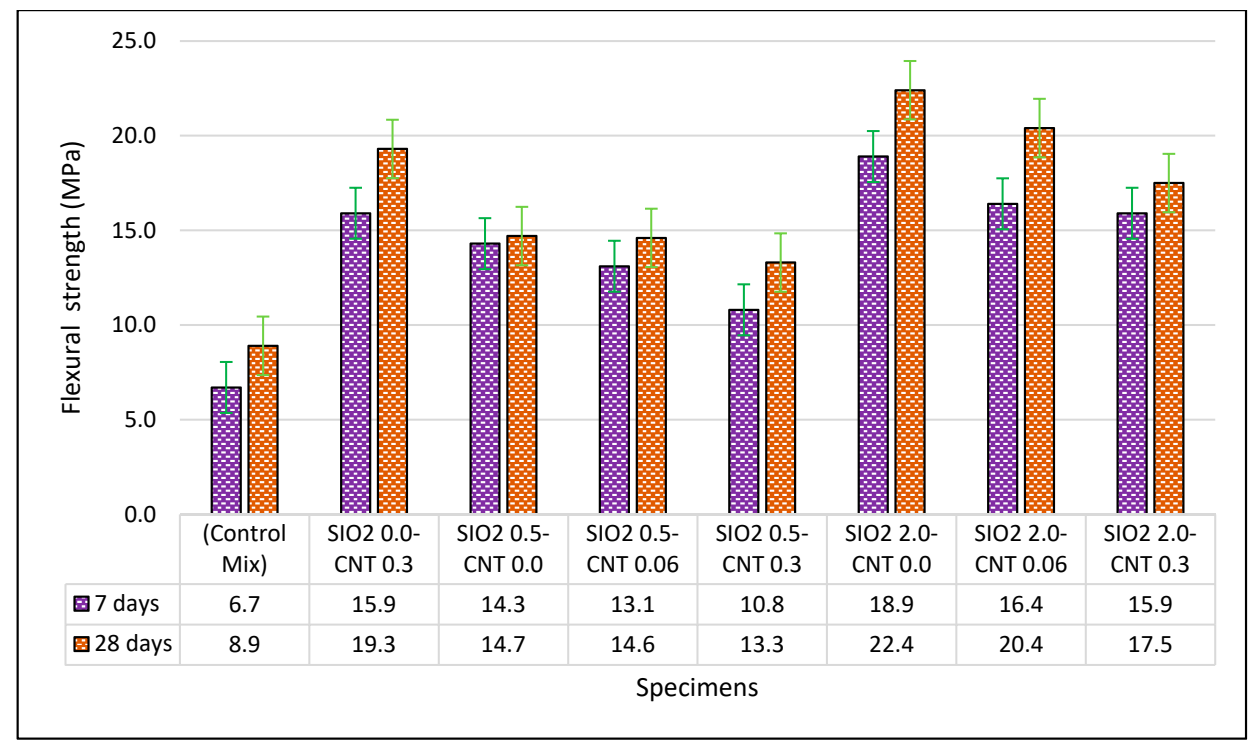

Figure 4. Flexural strength of cement paste specimens at the ages of 7 and 28 days.

In addition, the flexural strength for specimen $\mathrm{SiO}_{2} 0.0-\mathrm{CNT} 0.3$ shows a considerable improvement compared to the control mix during 7- and 28-day curing periods. The enhancement shows the positive effect of MWCNT, if NS is excluded from the cement paste. In this regard, Wang et al. [32] reported that MWCNT bridges across cracks and pores in the matrix. Following the FESEM analysis, they observed that during tension loads, MWCNT was pulled out from the cement paste's matrix. This response enhances the load-transfer during tension, which in turn increased the flexural strength, thus confirming the positive effect of MWCNT on the flexural strength. These observations show that the use of NS cannot always have promising effect on the flexural properties in the binary use with the MWCNT.

\subsection{Scanning Electron Microscope (SEM)}

SEM analysis was performed to assess the MWCNT dispersion quality and interaction of these nanoparticles in the cement paste. The evaluated dispersion concentrations were 0.0 and 0.3 wt. $\%$ CNT for specimens $\mathrm{SiO}_{2}$ 0.5-CNT 0.06 and $\mathrm{SiO}_{2} 2.0-\mathrm{CNT} 0.3$. The typical length for MWCNT in the experiment was between 5 and $15 \mu \mathrm{m}$. Possible damages of MWCNT during the dispersion process can reduce its length. Figure 5 illustrates the size and dispersion of the incorporated MWCNT with different dosages in the cement paste. Considering the special characteristics of MWCNT, such as its size and high aspect ratio (length to diameter), this nanoparticle can be more efficiently distributed in very fine scales, compared to other reinforcement materials, which in turn enhances the strength of cement paste by bridging the cracks at initial stages of crack propagation in the matrix. Figure 5a shows an individual MWCNT along with its micro-crack bridging and pull out behaviors. MWCNT are more distinguishable at early ages in that the cement hydration products can be further attracted by the large surface energy of this nonmaterial over the curing time. It was observed that an attraction by the C-S-H gel forms a coat over MWCNTs and 
mostly obscures them from detection. The combination of C-S-H and MWCNT, which can be orientated in various directions, leads to the formation of a multiphase product that contributes to enhancing the mechanical characteristics of the cement paste. The pull out response of MWCNT facilitates the load transfer in the cement paste and improves the flexural strength. MWCNTs should be uniformly dispersed within the cement paste to further enhance the strength characteristics in the matrix. Despite the use of an ultrasonic disrupter, some agglomeration and deficiencies in the binary use of MWCNT and NS within the cement paste were observed, which adversely affects the compressive and flexural strengths of the tested specimens (Figure $5 b, c$ ).
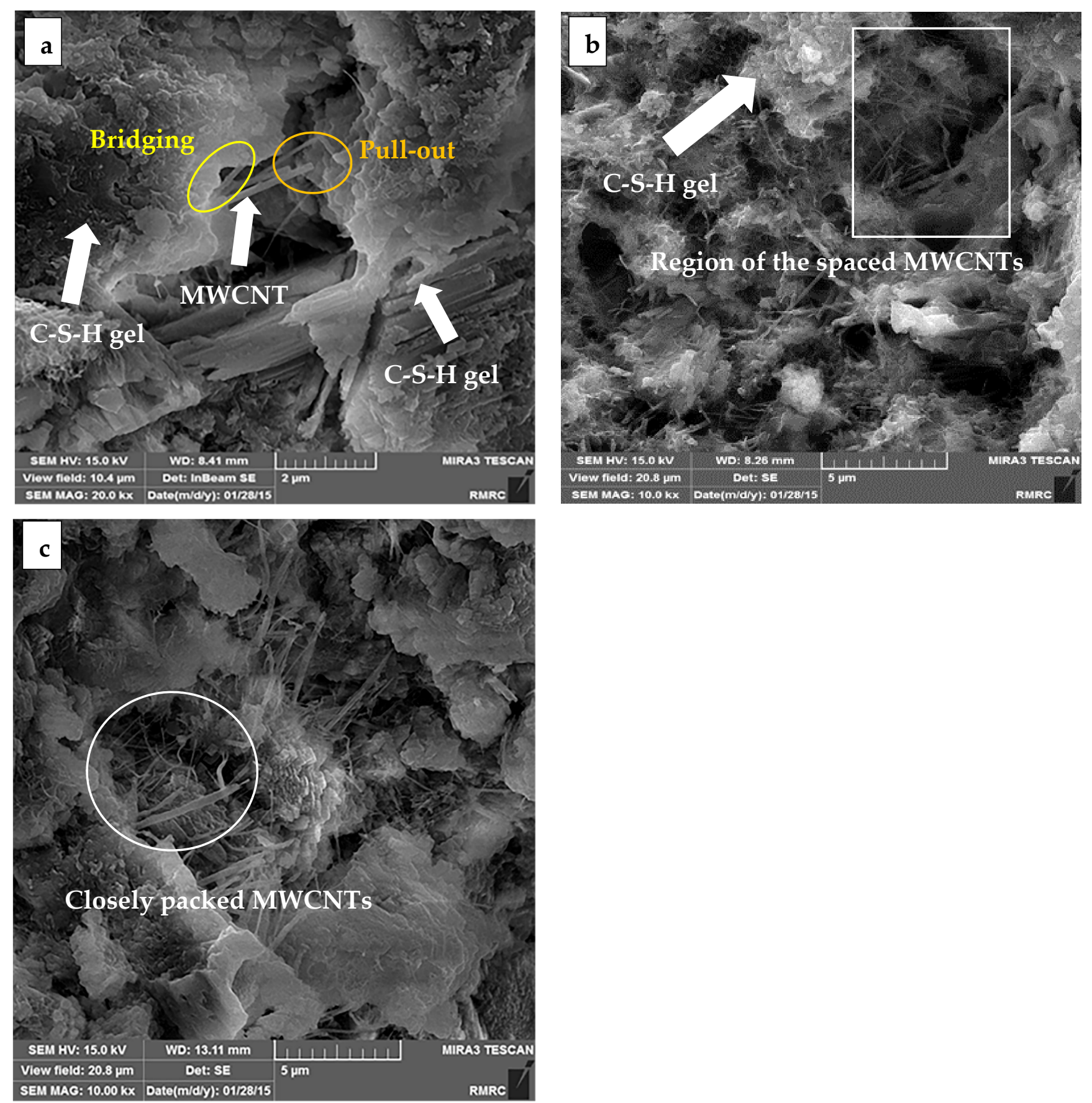

Figure 5. SEM images of the cement paste with w/c of 0.3: (a) bridging and pull out response of the $\mathrm{MWCNT}_{\text {in }}$ for the $\mathrm{SiO}_{2}$ 0.5-CNT 0.06 specimen; $(\mathbf{b})$ carbon nanotube's distribution in the prepared $\mathrm{SiO}_{2} 0.5-\mathrm{CNT} 0.06$ specimen; and $(\mathbf{c}) \mathrm{Ca}(\mathrm{OH})_{2}$ crystals developed from hydration in the $\mathrm{SiO}_{2} 2.0-\mathrm{CNT} 0.3$ specimen. 


\section{Conclusions}

In this study, silica nanoparticles and carbon nanotubes with different wt.\% were added to Portland cement paste to investigate their effect on improving the cement paste's mechanical properties. The primary outcomes of this study are summarized as follows:

- Following the results of conducted experiments in this study, the binary incorporation of MWCNT and NS cannot ensure the most influential effect on enhancing the cement paste's compressive and flexural strengths.

- The compressive strength of the cement paste was improved by adding nanoparticles, compared to the control mix. This enhancement was slightly higher in the 28-day specimens compared to the 7-day specimens. The maximum improvement at the ages of the 7 and 28 days were $111 \%$ and $117 \%$, respectively.

- The most considerable improvement in compressive strength was measured by using $2 \mathrm{wt} . \%$ of NS in the absence of MWCNT. This observation indicates that adding the NS in the presence of MWCNT cannot always result in the most favorable strength enhancement. Accordingly, the high water demand of MWCNT can adversely affect the mechanical characteristics of cement paste containing NS.

- Increasing the MWCNT dosage in the paste with a constant amount of NS led to a partial reduction in the compressive strength.

- Compared to the plain cement paste, incorporating MWCNT and NS enhanced the flexural strength of specimens for both the 7-day and 28-day curing periods. However, based on the measurements, the flexural strength increased up to $182 \%$ in the seven-day as well as $151 \%$ in the 28 -day specimens if MWCNT was excluded. These comparable results for both curing periods can be attributed to the weak bond of MWCNT in the presence of NS and its sliding performance in the matrix during the flexural loading.

- The reported flexural strengths show further enhancement by using MWCNT and excluding NS in the curation intervals. In this regard, the pull out response of the MWCNT facilitates the load-transfer during tension, which improves the flexural strength.

- The reported trends of reductions in the compressive and flexural strengths using the same percentages of NS and adding different percentages of MWCNT are comparable at similar error margins. These strength reductions indicate that, despite the high tensile strength of MWCNT, its effect on the flexural strength is only evident if MWCNT is separately incorporated.

- The SEM analysis showed bridging and pull out responses of MWCNT, which contributed to the enhancement of the cement paste's strength.

- It is recommended to further investigate the synergistic effect of nanoparticles in addition to other materials with different combinations in an effort to highlight not only the most promising outcomes, but also adverse influence of the binary or ternary use of nanoparticles.

Author Contributions: Conceptualization, V.F.; writing—original draft preparation, V.F., A.J.; project administration, V.F., M.K., A.J., M.R.F., M.Z., M.A.; visualization, V.F., M.K., A.J., M.R.F., M.Z., M.A.; methodology, V.F.; writing-review and editing, V.F., A.J.; investigation, V.F., M.R.F.; formal analysis, V.F.; supervision, V.F., M.K.; data curation, M.R.F.; funding acquisition, M.K. All authors have read and agreed to the published version of the manuscript.

Funding: The publication fees for this article are supported by the UNLV University Libraries Open Article Fund.

Data Availability Statement: The data presented in this study are available on request from the corresponding author.

Acknowledgments: The authors wish to express their sincere gratitude to Meysam Najimi and Jaeyun Moon for their valuable remarks regarding this research paper. 
Conflicts of Interest: The authors declare no conflict of interest that could affect the outcomes of the research study reported in the presented paper.

\section{References}

1. Balaguru, P.; Chong, K. Nanotechnology and Concrete: Research Opportunities; ACI Special Publication; American Concrete Institute: Farmington Hills, MI, USA, 2008; pp. 15-28.

2. Jazaei, R.; Karakouzian, M.; O'Toole, B.; Moon, J.; Gharehdaghi, S. Energy absorption of cementitious composites incorporating carbon nanotubes subjected to low-velocity impact tests. In Forensic Engineering 2018: Forging Forensic Frontiers, Proceedings of the 8th Congress on Forensic Engineering, Austin, TX, USA, 29 November-2 December 2018; American Society of Civil Engineers: New York, NY, USA, 2018; pp. 717-725. [CrossRef]

3. Gong, K.; Pan, Z.; Korayem, A.H.; Qiu, L.; Li, D.; Collins, F.; Wang, C.M.; Duan, W.H. Reinforcing effects of graphene oxide on portland cement paste. J. Mater. Civ. Eng. 2015, 27, 1-6. [CrossRef]

4. Muzenski, S.; Flores-Vivian, I.; Farahi, B.; Sobolev, K. Towards ultrahigh performance concrete produced with aluminum oxide nanofibers and reduced quantities of silica fume. Nanomaterials 2020, 10, 2291. [CrossRef]

5. Tahmouresi, B.; Nemati, P.; Asadi, M.A.; Saradar, A.; Mohtasham Moein, M. Mechanical strength and microstructure of engineered cementitious composites: A new configuration for direct tensile strength, experimental and numerical analysis. Constr. Build. Mater. 2021, 269, 121361. [CrossRef]

6. Satvati, S.; Cetin, B.; Ashlock, J.C.; Ceylan, H.; Rutherford, C. Binding Capacity of Quarry Fines for Granular Aggregates. In Geo-Congress 2020: Geotechnical Earthquake Engineering and Special Topics; American Society of Civil Engineers: Reston, VA, USA, 2020; pp. 457-466. [CrossRef]

7. Jarrah, M.; Najafabadi, E.P.; Khaneghahi, M.H.; Oskouei, A.V. The effect of elevated temperatures on the tensile performance of GFRP and CFRP sheets. Constr. Build. Mater. 2018, 190, 38-52. [CrossRef]

8. Toufigh, V.; Abyaneh, M.J.; Jafari, K. Study of behavior of concrete under axial and triaxial compression. ACI Mater. J. 2017, 114, 619-629. [CrossRef]

9. Jafari, K.; Toufigh, V. Experimental and analytical evaluation of rubberized polymer concrete. Constr. Build. Mater. 2017, 155, 495-510. [CrossRef]

10. Naeimi, N.; Moustafa, M.A. Compressive behavior and stress-strain relationships of confined and unconfined UHPC. Constr. Build. Mater. 2021, 272, 121844. [CrossRef]

11. Karimipour, A.; Ghalehnovi, M.; de Brito, J.; Attari, M. The effect of polypropylene fibres on the compressive strength, impact and heat resistance of self-compacting concrete. Structures 2020, 25, 72-87. [CrossRef]

12. Afsharhasani, R.; Karakouzian, M.; Farhangi, V. Effect of competent caliche layers on measuring the capacity of axially loaded drilled shafts using the osterberg test. Appl. Sci. 2020, 10, 6169. [CrossRef]

13. Salimi, J.; Ramezanianpour, A.M.; Moradi, M.J. Studying the effect of low reactivity metakaolin on free and restrained shrinkage of high performance concrete. J. Build. Eng. 2020, 28, 101053. [CrossRef]

14. Shahmansouri, A.A.; Akbarzadeh Bengar, H.; AzariJafari, H. Life cycle assessment of eco-friendly concrete mixtures incorporating natural zeolite in sulfate-aggressive environment. Constr. Build. Mater. 2021, 268, 121136. [CrossRef]

15. Li, G.; Liu, Q.; Niu, M.; Cao, L.; Nan, B.; Shi, C. Characteristic of silica nanoparticles on mechanical performance and microstructure of sulphoaluminate cement/ordinary Portland cement binary blends. Constr. Build. Mater. 2020, 242, 118158. [CrossRef]

16. Sargam, Y.; Wang, K. Influence of dispersants and dispersion on properties of nanosilica modified cement-based materials. Cem. Concr. Compos. 2021, 118, 103969. [CrossRef]

17. Najigivi, A.; Khaloo, A.; Iraji Zad, A.; Abdul Rashid, S. Investigating the effects of using different types of $\mathrm{SiO}_{2}$ nanoparticles on the mechanical properties of binary blended concrete. Compos. Part B Eng. 2013, 54, 52-58. [CrossRef]

18. MacLeod, A.J.N.; Fehervari, A.; Gates, W.P.; Garcez, E.O.; Aldridge, L.P.; Collins, F. Enhancing fresh properties and strength of concrete with a pre-dispersed carbon nanotube liquid admixture. Constr. Build. Mater. 2020, 247, 118524. [CrossRef]

19. Yakovlev, G.I.; Skripkiunas, G.; Polianskich, I.S.; Lahayne, O.; Eberhardsteiner, J.; Urkhanova, L.A.; Pudov, I.A.; Sychugov, S.V.; Karpova, E.A.; Sen'Kov, S.A. Modification of Cement Matrix Using Carbon Nanotube Dispersions and Nanosilica. Procedia Eng. 2017, 172, 1261-1269. [CrossRef]

20. Balapour, M.; Joshaghani, A.; Althoey, F. Nano-SiO ${ }_{2}$ contribution to mechanical, durability, fresh and microstructural characteristics of concrete: A review. Constr. Build. Mater. 2018, 181, 27-41. [CrossRef]

21. Mohammadyan-Yasouj, S.E.; Ghaderi, A. Experimental investigation of waste glass powder, basalt fibre, and carbon nanotube on the mechanical properties of concrete. Constr. Build. Mater. 2020, 252, 119115. [CrossRef]

22. Stynoski, P.; Mondal, P.; Marsh, C. Effects of silica additives on fracture properties of carbon nanotube and carbon fiber reinforced Portland cement mortar. Cem. Concr. Compos. 2015, 55, 232-240. [CrossRef]

23. Wang, Q.; Wang, J.; Lu, C.X.; Liu, B.W.; Zhang, K.; Li, C.Z. Influence of graphene oxide additions on the microstructure and mechanical strength of cement. Xinxing Tan Cailiao/New Carbon Mater. 2015, 30, 349-356. [CrossRef]

24. Nazari, A.; Riahi, S. The effects of zinc dioxide nanoparticles on flexural strength of self-compacting concrete. Compos. Part B Eng. 2011, 42, 167-175. [CrossRef]

25. Karimipour, A.; Ghalehnovi, M. Influence of steel fibres on the mechanical and physical performance of self-compacting concrete manufactured with waste materials and fillers. Constr. Build. Mater. 2021, 267, 121806. [CrossRef] 
26. Karimipour, A.; Edalati, M.; de Brito, J. Biaxial mechanical behaviour of polypropylene fibres reinforced self-compacting concrete. Constr. Build. Mater. 2021, 278, 122416. [CrossRef]

27. Gebretsadik, B.; Jadidi, K.; Farhangi, V.; Karakouzian, M. Application of Ultrasonic Measurements for the Evaluation of Steel Fiber Reinforced Concrete. Eng. Technol. Appl. Sci. Res. 2021, 11, 6662-6667. [CrossRef]

28. Sadrmomtazi, A.; Gashti, S.H.; Tahmouresi, B. Residual strength and microstructure of fiber reinforced self-compacting concrete exposed to high temperatures. Constr. Build. Mater. 2020, 230, 116969. [CrossRef]

29. Roshani, M.M.; Kargar, S.H.; Farhangi, V.; Karakouzian, M. Predicting the effect of fly ash on concrete's mechanical properties by ann. Sustainability 2021, 13, 1469. [CrossRef]

30. Aydın, A.C.; Nasl, V.J.; Kotan, T. The synergic influence of nano-silica and carbon nano tube on self-compacting concrete. J. Build. Eng. 2018, 20, 467-475. [CrossRef]

31. Wille, K.; Loh, K.J. Nanoengineering ultra-high-performance concrete with multiwalled carbon nanotubes. Transp. Res. Rec. 2010, 2142, 119-126. [CrossRef]

32. Wang, B.; Han, Y.; Liu, S. Effect of highly dispersed carbon nanotubes on the flexural toughness of cement-based composites. Constr. Build. Mater. 2013, 46, 8-12. [CrossRef]

33. Ghosal, M.; Chakraborty, A.K. Application of Nanomaterials on Cement Mortar and Concrete: A Study. IUP J. Struct. Eng. 2017, 10, 7-15.

34. Joshaghani, A. Evaluating the effects of titanium dioxide $\left(\mathrm{TiO}_{2}\right)$ and carbon-nanofibers $(\mathrm{CNF})$ as cement partial replacement on concrete properties. MOJ Civ. Eng. 2018, 4, 00094. [CrossRef]

35. Kang, J.; Al-Sabah, S.; Théo, R. Effect of single-walled carbon nanotubes on strength properties of cement composites. Materials 2020, 13, 1305. [CrossRef]

36. Vesmawala, G.R.; Vaghela, A.R.; Yadav, K.D.; Patil, Y. Effectiveness of polycarboxylate as a dispersant of carbon nanotubes in concrete. Mater. Today Proc. 2020, 28, 10-14. [CrossRef]

37. Hu, S.; Xu, Y.; Wang, J.; Zhang, P.; Guo, J. Modification effects of carbon nanotube dispersion on the mechanical properties, pore structure, and microstructure of cement mortar. Materials 2020, 13, 1101. [CrossRef] [PubMed]

38. Vidivelli, B.; Ashwini, B. A Study on Carbon Nanotube (CNT) in Cement Mortar. Int. J. Eng. Sci. Comput. 2018, 1, 481-489.

39. Konsta-Gdoutos, M.S.; Metaxa, Z.S.; Shah, S.P. Highly dispersed carbon nanotube reinforced cement based materials. Cem. Concr. Res. 2010, 40, 1052-1059. [CrossRef]

40. Parveen, S.; Rana, S.; Fangueiro, R.; Paiva, M.C. Microstructure and mechanical properties of carbon nanotube reinforced cementitious composites developed using a novel dispersion technique. Cem. Concr. Res. 2015, 73, 215-227. [CrossRef]

41. Mohsen, M.O.; Al-Nuaimi, N.; Abu Al-Rub, R.K.; Senouci, A.; Bani-Hani, K.A. Effect of mixing duration on flexural strength of multi walled carbon nanotubes cementitious composites. Constr. Build. Mater. 2016, 126, 586-598. [CrossRef]

42. Xu, S.; Liu, J.; Li, Q. Mechanical properties and microstructure of multi-walled carbon nanotube-reinforced cement paste. Constr. Build. Mater. 2015, 76, 16-23. [CrossRef]

43. Keriene, J.; Kligys, M.; Laukaitis, A.; Yakovlev, G.; Špokauskas, A.; Aleknevičius, M. The influence of multi-walled carbon nanotubes additive on properties of non-autoclaved and autoclaved aerated concretes. Constr. Build. Mater. 2013, 49, 527-535. [CrossRef]

44. Najafishad, S.; Manesh, H.D.; Zebarjad, S.M.; Hataf, N.; Mazaheri, Y. Production and investigation of mechanical properties and electrical resistivity of cement-matrix nanocomposites with graphene oxide and carbon nanotube reinforcements. Arch. Civ. Mech. Eng. 2020, 20, 1-13. [CrossRef]

45. Malakooti, A.; Theh, W.S.; Sadati, S.M.S.; Ceylan, H.; Kim, S.; Mina, M.; Cetin, K.; Taylor, P.C. Design and Full-scale Implementation of the Largest Operational Electrically Conductive Concrete Heated Pavement System. Constr. Build. Mater. 2020, $255,119229$. [CrossRef]

46. Frolov, A.; Chumadova, L.; Cherkashin, A.; Akimov, L. Prospects of use and impact of nanoparticles on the properties of high-strength concrete. Appl. Mech. Mater. 2014, 584-586, 1416-1424. [CrossRef]

47. Karimipour, A.; Rakhshanimehr, M.; Ghalehnovi, M.; de Brito, J. Effect of different fibre types on the structural performance of recycled aggregate concrete beams with spliced bars. J. Build. Eng. 2021, 38, 102090. [CrossRef]

48. Daneshvar, K.; Moradi, M.J.; Amooie, M.; Chen, S.; Mahdavi, G.; Hariri-Ardebili, M.A. Response of low-percentage FRC slabs under impact loading: Experimental, numerical, and soft computing methods. Structures 2020, 27, 975-988. [CrossRef]

49. Shahmansouri, A.A.; Yazdani, M.; Ghanbari, S.; Akbarzadeh Bengar, H.; Jafari, A.; Farrokh Ghatte, H. Artificial neural network model to predict the compressive strength of eco-friendly geopolymer concrete incorporating silica fume and natural zeolite. J. Clean. Prod. 2021, 279, 123697. [CrossRef]

50. Satvati, S.; Nahvi, A.; Cetin, B.; Ashlock, J.C.; Jahren, C.T.; Ceylan, H. Performance-based economic analysis to find the sustainable aggregate option for a granular roadway. Transp. Geotech. 2021, 26, 100410. [CrossRef]

51. Sikora, P.; Abd Elrahman, M.; Chung, S.Y.; Cendrowski, K.; Mijowska, E.; Stephan, D. Mechanical and microstructural properties of cement pastes containing carbon nanotubes and carbon nanotube-silica core-shell structures, exposed to elevated temperature. Cem. Concr. Compos. 2019, 95, 193-204. [CrossRef]

52. Narasimman, K.; Jassam, T.M.; Velayutham, T.S.; Yaseer, M.M.M.; Ruzaimah, R. The synergic influence of carbon nanotube and nanosilica on the compressive strength of lightweight concrete. J. Build. Eng. 2020, 32, 101719. [CrossRef] 
53. Garg, M.; Das, C.S.; Gupta, R. Use of silica particles to improve dispersion of -COOH CNTs/carbon fibers to produce HyFRCC. Constr. Build. Mater. 2020, 250, 118777. [CrossRef]

54. ASTM C150. Standard Specification for Portland Cement, Annual Book of ASTM Standards; ASTM International: West Conshohocken, PA, USA, 2001.

55. ASTM C109/C109M-02. Standard Test Method for Compressive Strength of Hydraulic Cement Mortars (Using 2-in. or [50 mm] Cube Specimens); Annual Book of ASTM Standard; ASTM International: West Conshohocken, PA, USA, 2005; Volume 04.01.

56. Cnts, P.; Cnts, A. Amine-Functionalized Carbon Nanotubes Applications; Elsevier: Amsterdam, The Netherland, 2015 ; pp. 19-27.

57. Liu, Q.; Ma, J. Mechanical properties of modified nano-concrete. Acta Microsc. 2020, 29, 368-377.

58. El-Feky, M.S.; El-Khodary, S.A.; Morsy, M. Optimization of hybrid cement composite with carbon nanotubes and nano silica using response surface design. Egypt. J. Chem. 2019, 62, 57-67. [CrossRef]

59. Kong, D.; Du, X.; Wei, S.; Zhang, H.; Yang, Y.; Shah, S.P. Influence of nano-silica agglomeration on microstructure and properties of the hardened cement-based materials. Constr. Build. Mater. 2012, 37, 707-715. [CrossRef]

60. Yousefi, A.; Allahverdi, A.; Hejazi, P. Effective dispersion of nano- $\mathrm{TiO}_{2}$ powder for enhancement of photocatalytic properties in cement mixes. Constr. Build. Mater. 2013, 41, 224-230. [CrossRef]

61. Liu, J.; Fu, J.; Ni, T.; Yang, Y. Fracture toughness improvement of multi-wall carbon nanotubes/graphene sheets reinforced cement paste. Constr. Build. Mater. 2019, 200, 530-538. [CrossRef]

62. Collins, F.; Lambert, J.; Duan, W.H. The influences of admixtures on the dispersion, workability, and strength of carbon nanotube-OPC paste mixtures. Cem. Concr. Compos. 2012, 34, 201-207. [CrossRef]

63. Pan, Z.; He, L.; Qiu, L.; Korayem, A.H.; Li, G.; Zhu, J.W.; Collins, F.; Li, D.; Duan, W.H.; Wang, M.C. Mechanical properties and microstructure of a graphene oxide-cement composite. Cem. Concr. Compos. 2015, 58, 140-147. [CrossRef]

64. Li, H.; Xiao, H.G.; Yuan, J.; Ou, J. Microstructure of cement mortar with nano-particles. Compos. Part B Eng. 2004, 35, 185-189. [CrossRef]

65. ASTM C109/C109M-02. Standard Test Method for Compressive Strength of Hydraulic Cement Mortars; ASTM International: West Conshohocken, PA, USA, 2002; Volume 04.

66. ASTM C348-20. Standard Test Method for Flexural Strength of Hydraulic-Cement Mortars; ASTM International: West Conshohocken, PA, USA, 2020; Volume 1.

67. Haruehansapong, S.; Pulngern, T.; Chucheepsakul, S. Effect of the particle size of nanosilica on the compressive strength and the optimum replacement content of cement mortar containing nano-SiO ${ }_{2}$. Constr. Build. Mater. 2014, 50, 471-477. [CrossRef]

68. Mohammed, A.; Rafiq, S.; Mahmood, W.; Noaman, R.; Ghafor, K.; Qadir, W.; Kadhum, Q. Characterization and modeling the flow behavior and compression strength of the cement paste modified with silica nano-size at different temperature conditions. Constr. Build. Mater. 2020, 257, 119590. [CrossRef]

69. Quercia, G.; Hüsken, G.; Brouwers, H.J.H. Water demand of amorphous nano silica and its impact on the workability of cement paste. Cem. Concr. Res. 2012, 42, 344-357. [CrossRef]

70. Sobolkina, A.; Mechtcherine, V.; Khavrus, V.; Maier, D.; Mende, M.; Ritschel, M.; Leonhardt, A. Dispersion of carbon nanotubes and its influence on the mechanical properties of the cement matrix. Cem. Concr. Compos. 2012, 34, 1104-1113. [CrossRef]

71. Zhou, C.; Li, F.; Hu, J.; Ren, M.; Wei, J.; Yu, Q. Enhanced mechanical properties of cement paste by hybrid graphene oxide/carbon nanotubes. Constr. Build. Mater. 2017, 134, 336-345. [CrossRef]

72. Güler, Ö.; Cacim, N.N.; Evin, E.; Yahia, I.S. The synergistic effect of CNTs-polymeric surfactant on the properties of concrete nanocomposites: Comparative study. J. Compos. Mater. 2020. [CrossRef]

73. Alafogianni, P.; Dassios, K.; Tsakiroglou, C.D.; Matikas, T.E.; Barkoula, N.M. Effect of CNT addition and dispersive agents on the transport properties and microstructure of cement mortars. Constr. Build. Mater. 2019, 197, 251-261. [CrossRef]

74. Han, B.; Sun, S.; Ding, S.; Zhang, L.; Dong, S.; Yu, X. Nano Carbon Material-Filled Cementitious Composites: Fabrication, Properties, and Application. In Innovative Developments of Advanced Multifunctional Nanocomposites in Civil and Structural Engineering; Woodhead Publishing Ltd.: Cambridge, UK, 2016; pp. 153-181. [CrossRef]

75. Cwirzen, A.; Habermehl-Cwirzen, K.; Nasibulin, A.G.; Kaupinen, E.I.; Mudimela, P.R.; Penttala, V. SEM/AFM studies of cementitious binder modified by MWCNT and nano-sized Fe needles. Mater. Charact. 2009, 60, 735-740. [CrossRef] 